\title{
Toilet training practices in Nigerian children
}

\author{
A U Solarin, ${ }^{1}$ MPhil, Cert Nephrol (SA) Paed, FWAC Paed, MBBS; O A Olutekunbi, ${ }^{2}$ FWAC Paed, MBBS; \\ A D Madise-Wobo, ${ }^{1}$ FMC Paed, MSc, MBBS; I Senbanjo, ${ }^{1}$ FWAC Paed, MSc, MB ChB
}

\author{
${ }^{1}$ Department of Paediatrics, Lagos State University Teaching Hospital, Lagos, Nigeria \\ ${ }^{2}$ Department of Paediatrics, Gbagada General Hospital, Lagos, Nigeria
}

Corresponding author: A U Solarin (asolar234@gmail.com)

\begin{abstract}
Background. This study reports on toilet training with a focus on the effect of age, methods used, and factors that can affect urinary incontinence in Nigerian children.

Methods. This was a cross-sectional hospital-based study carried out in public and private hospitals in South-Western Nigeria. A questionnaire was used to obtain information about toilet training practices from 350 adults, who toilet trained 474 children.

Results. The adults had previously toilet trained children $1-18$ years old. In this study, toilet training commenced at $\leq 12$ months, during the day and night in $40.6 \%$ and $33.4 \%$ of children, respectively. Of the 350 parents/guardians, 141 (47.7\%) commenced toilet training by waking children from their afternoon nap. The most common method was allowing the child to urinate at fixed time intervals, while the least common was a reward/punishment system. Furthermore, age was considered as the most common indicator to commence toilet training. For $36.9 \%$ of the children, training lasted 1 - 6 months. Daytime continence was achieved by $33.4 \%$ of children at $\leq 12$ months old, and night-time continence was achieved in $29.7 \%$ of children between 12 and 18 months old. By 30 months, $91.1 \%$ and $86.9 \%$ had attained day- and night-time continence, respectively, and only $8.6 \%$ of the children were incontinent at night.

Conclusion. Assisted infant toilet training is still practised among Nigerian parents despite the influence and the trends in the developed countries. The age at initiation and completion of toilet training was lower than those reported for developed countries.
\end{abstract}

S Afr J Child Health 2017;11(3):122-128. DOI:10.7196/SAJCH.2017.v11i3.1287

Toilet training is an important aspect of early childhood developmental milestones, and it may be quite challenging. It involves a complex integration of neurological, muscular, and behavioural mechanisms. ${ }^{[1,2]}$ Toilet training is also influenced by physiological, psychological and sociocultural factors. ${ }^{[3,4]}$ Failure of toilet training may result in significant physical and psychological consequences like a sense of failure through partial loss of autonomy. ${ }^{[5]}$

Different opinions on the optimal time to initiate toilet training cut across different cultures and beliefs. ${ }^{[2,6]}$ Five to six decades ago, toilet training in Western countries was initiated at an earlier age compared with the current initiation age. ${ }^{[2,4]}$ For example, in the USA, the median age of initiating toilet training ranged from 25 to 27 months in the 80 s; it had increased to $n$ (SD) of 36.8 (6.1) months in $2003 .{ }^{[7]}$ In a report, toilet training before the age of 18 months had already started $\sim 60$ years ago, while modern parents usually start the training after 18 months. ${ }^{[4]}$ One of the reasons for the later initiation age of toilet training may be because of the recommendations by the American Academy of Pediatrics (AAP). According to the AAP, starting toilet training before the age of 2 years is not recommended because the readiness skills and physical abilities required only develop between age 18 and 30 months. ${ }^{[8]}$ In addition to the AAP's recommendation, the introduction of disposable diapers, more efficient laundry facilities and both parents working may contribute to the later age of commencing toilet training. ${ }^{[9]}$ There are arguments against early and late initiation of toilet training. A delay in toilet training was considered to be related to increased frequency of dysfunctional voiding in children. ${ }^{[4,10]}$ For example, in the United Kingdom, a cohort study showed that when toilet training commenced after 24 months of age there was an association with diurnal enuresis and delayed acquisition of bladder control. ${ }^{[11]}$ There were also fears that toilet training at an earlier age may result in voiding dysfunction. ${ }^{[12]}$ However, Duong et al. ${ }^{[13]}$ dispelled that fear in a study that investigated early initiation of toilet training in Vietnamese girls. In that study, it was noted that toilet training that was initiated at $<12$ months did not result in voiding dysfunction.
There are different types of toilet training methods available. In the Western communities two predominant methods are used; the 'childoriented' method of Brazelton et al. ${ }^{[14]}$ and the Azrin and Foxx method. ${ }^{[15]}$ Other methods include variations of operant conditioning, assisted infant toilet training, and the Spock method. ${ }^{\left[{ }^{[9]}\right.}$ In 1962 Brazelton et al. ${ }^{[14]}$ described the child-oriented approach. It is based on the principle that the child must gently but systematically be encouraged to experiment toileting behaviour. The Azrin and Foxx ${ }^{[15]}$ method, on the other hand, is more intensive and structured. However, the method has been associated with reported side-effects of temper tantrums, hitting and avoidance behaviour. Less known, but applied for many centuries in China, India, Africa, South and Central America, is assisted infant toilet training. The caregivers play a key role by observing the child's evacuation signals and when they occur, place them in a special position. It is important to note that although recent guidelines of the AAP ${ }^{[16,17]}$ and the Canadian Pediatric Society ${ }^{[18]}$ are based on the child-oriented approach ${ }^{[9]}$ and Azrin and Foxx method, ${ }^{[15]}$ no efficacy studies or randomised controlled trials have been conducted.

Recent studies have identified incorrect toilet training as being predictive of persistent urinary symptoms, such as urinary incontinence, enuresis, recurrent urinary tract infection and childhood constipation. ${ }^{[19-21]}$ Urinary incontinence has an impact on both the child and family. It affects the self-esteem, interpersonal relationships and school performance of the children, as described in detail by Mota and Barros ${ }^{[22]}$ in a previous review. Primary enuresis is related to the presence of nocturnal polyuria, difficulties waking from sleep and reduced bladder capacity, whereas secondary enuresis is more related to urinary infections, diabetes mellitus and emotional disorders. ${ }^{[22-25]}$ Coercive or permissive methods of toilet training may be associated with the development of enuresis and encopresis. ${ }^{[14,26,27]}$ In an analysis of the prevalence of enuresis according to the age of acquisition of daytime urinary continence, Chiozza et $a l .{ }^{[28]}$ observed that, among children who achieved bladder and bowel control after 36 months, the prevalence of enuresis was $17.1 \%$, whereas children who achieved control before 25 months and between 25 and 36 months had prevalence rates of $2.7 \%$ and $5.8 \%$, respectively. These findings 
suggest that starting toilet training later may promote enuresis. Certain interventions to treat enuresis employ techniques of toilet retraining and provide guidance on regularity of elimination habits. ${ }^{[29,30]}$

In Africa there is limited literature focusing specifically on the age aspect of toilet training practices. This study aimed to report on methods at the time of initiation and the time of completion of toilet training, as well as any relationships among these factors and enuresis in our setting.

\section{Method \\ Study design}

This was a cross-sectional hospital-based study designed to answer three major research questions:

- At what age do parents/caregivers commence toilet training on their children/wards?

- What is the age at attainment of day- and night-time urinary continence?

- What is/are the toilet training method/s used by parents/caregivers on their children?

\section{Study setting}

The study was carried out in private and government hospitals in two states in South-Western Nigeria. The participants from the public hospital were residents of Lagos State, while those from the private hospital were residents of Ogun State. Lagos State is a densely populated cosmopolitan urban setting, while Ogun State is suburban and less densely populated. The study was conducted between April and July 2016.

\section{Data acquisition}

A tested questionnaire was used to obtain information from the participants. The questionnaire was adapted from a previous questionnaire which had been validated and used by Bakker and Wyndaele. ${ }^{[4]}$

\section{Participants}

The participants were parents and caregivers who presented to the hospital for various reasons. The aim of the study was explained to the parents/ caregivers of the children and those who gave verbal consent were included in the study. The parents were recruited consecutively until the minimum sample size was achieved. The socioeconomic classes of the participants were documented using the Oyedeji classification. ${ }^{[31]}$ Those in social classes 1 and 2 were regarded as upper class, those in class 3 as middle class, while those in classes 4 and 5 were in a lower socioeconomic class.

The following participants were excluded: parents of children with neurological problems, e.g. spinal dysraphism, hydrocephalus, and cerebral palsy, as well as those who had children with urogenital abnormalities.

\section{Variables}

The tested questionnaire was used to obtain relevant information from the participants. The outcome variables were: age at attainment of day- and night-time urinary continence; toilet training methods used; duration of toilet training; and factors which affected the age at attainment of urinary continence.

A potential challenge was failure to understand the questions in the questionnaire. To avoid this, the questionnaire was pretested in a different subset of caregivers to avoid ambiguity.

\section{Data measurement}

The source of the data was from the questionnaire completed by the participants. The variables that were normally distributed were summarised with mean and standard deviation.

For description of the first two outcome variable outcomes, mean and mode were used to analyse those variables. The $\chi^{2}$ test was used to analyse the relationship between variables to ascertain which factors affected the age of attainment of urinary continence. An inter-group comparison was also done using $\chi^{2}$ test; $p<0.05$ indicated statistical significance.

Table 1. Sociodemographic characteristics of parents $(N=350)$

\begin{tabular}{|c|c|c|c|c|}
\hline & \multicolumn{3}{|c|}{ Type of centre } & \multirow[b]{2}{*}{$p$-value } \\
\hline & Public ( $n=250), n(\%)$ & Private $(n=100), n(\%)$ & Total, $\boldsymbol{n}(\%)$ & \\
\hline \multicolumn{5}{|c|}{ Father's level of education } \\
\hline None & $3(1.2)$ & $1(1.0)$ & $4(1.1)$ & \multirow[t]{5}{*}{0.616} \\
\hline Primary & $9(3.6)$ & $3(3.0)$ & $12(3.4)$ & \\
\hline Secondary & $51(20.4)$ & $24(24.0)$ & $75(21.4)$ & \\
\hline $\mathrm{BSc} / \mathrm{HND}$ & $176(70.4)$ & $64(64.0)$ & $240(68.6)$ & \\
\hline Postgraduate & $11(4.4)$ & $8(8.0)$ & $19(5.4)$ & \\
\hline \multicolumn{5}{|c|}{ Mother's level of education } \\
\hline Primary & $3(1.2)$ & $2(2.0)$ & $5(1.4)$ & \multirow[t]{4}{*}{0.574} \\
\hline Secondary & $67(26.8)$ & $27(27.0)$ & $94(26.9)$ & \\
\hline $\mathrm{BSc} / \mathrm{HND}$ & $174(69.6)$ & $66(66.0)$ & $240(68.6)$ & \\
\hline Postgraduate & $6(2.4)$ & $5(5.0)$ & $11(3.1)$ & \\
\hline \multicolumn{5}{|l|}{ Father's occupation } \\
\hline None & $6(2.4)$ & $1(1.0)$ & $7(2.0)$ & \multirow[t]{6}{*}{0.621} \\
\hline Civil servant & $64(25.6)$ & $20(20.0)$ & $84(24.0)$ & \\
\hline Artisan & $41(16.4)$ & $11(1.0)$ & $52(14.9)$ & \\
\hline Businessman & $85(34.0)$ & $31(31.0)$ & $116(33.1)$ & \\
\hline Student & $0(0.0)$ & $0(0.0)$ & $0(0.0)$ & \\
\hline Professional & $54(21.6)$ & $37(37)$ & $91(26.0)$ & \\
\hline \multicolumn{5}{|l|}{ Mother's occupation } \\
\hline None & $12(4.8)$ & $3(3.0)$ & $15(4.3)$ & \multirow[t]{6}{*}{0.432} \\
\hline Civil servant & $81(32.4)$ & $18(18.0)$ & $99(28.2)$ & \\
\hline Artisan & $16(6.4)$ & $18(18.0)$ & $34(9.7)$ & \\
\hline Businesswoman & $101(40.4)$ & $21(21.0)$ & $122(34.9)$ & \\
\hline Student & $9(3.6)$ & $2(2.0)$ & $11(3.1)$ & \\
\hline Professional & $31(12.4)$ & $38(38.0)$ & $69(19.7)$ & \\
\hline
\end{tabular}




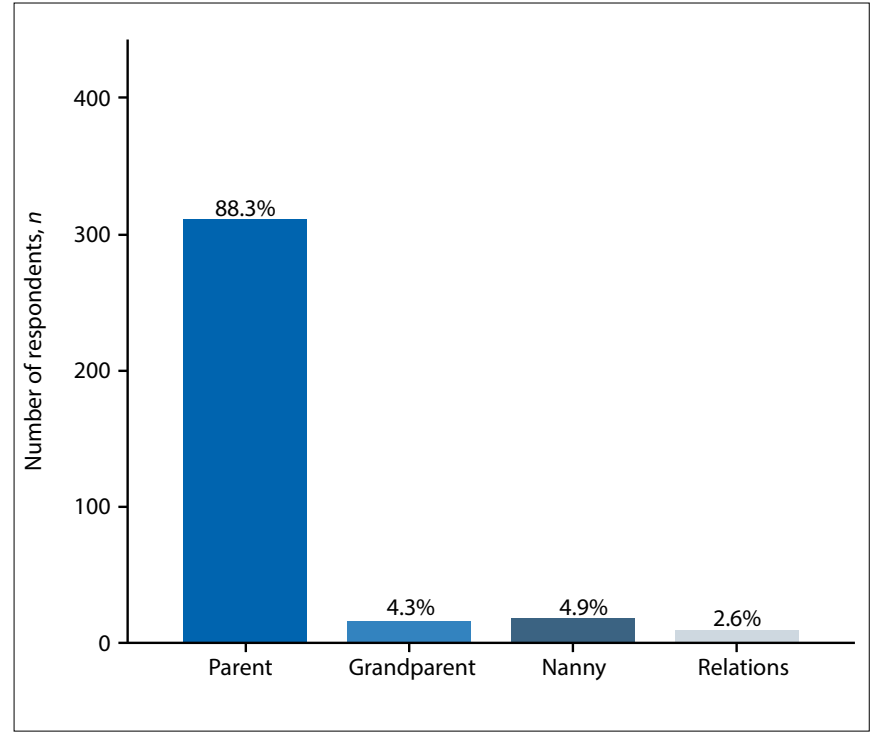

Fig. 1. Person in charge of toilet training $(N=350)$.

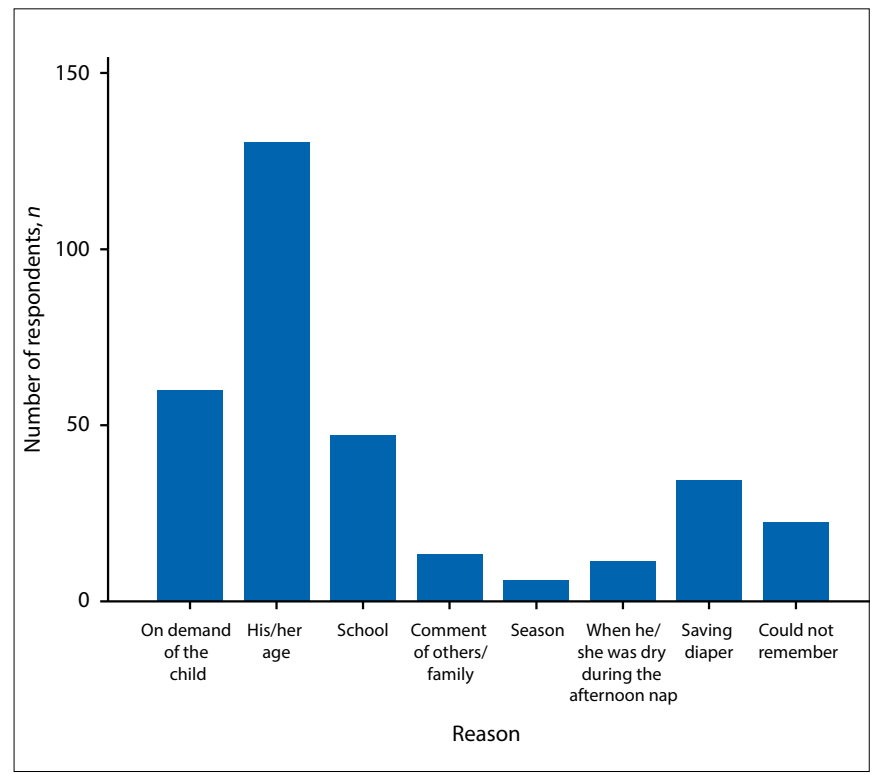

Fig. 2. Reasons for initiating toilet training during the day $(N=350)$.

\section{Results \\ Sociodemographic characteristics of the study participants}

A total of 350 parents/guardians participated in the study. The sociodemographic characteristics of the caregivers who participated in the study were defined (Table 1). The mean (SD) ages of the caregivers were $42(6.80)$ and 36.41 (7.15) for the males and females, respectively. The majority of the parents $(284(81.9 \%))$, were Christian, while 66 (18.1\%) practised Islam. Most of the parents had a tertiary level of education and there was no significant difference in the level of education of the parents in the different hospitals $(p>0.05)$. The majority of the parents were either businessmen or businesswomen and professionals, with no significant difference in the occupations of the parents in the different hospitals $(p>0.05)$. The social class of the parents in both group of hospitals was social class 4 (lower social class based on educational level and occupation of both parents).

All of the study participants had children. Of the 350 parents/ caregivers who participated in the study, information was obtained for 474 children. A total of $22(6.3 \%)$ participants had grandchildren. The children were between 1 and 18 years old. The majority of the
Table 2. Method and age of commencement of toilet training including types of diapers and reasons for commencement $(N=350)$

\begin{tabular}{ll}
\hline Variable & $\boldsymbol{n}(\%)$ \\
\hline How grandparent participated in toilet & \\
training & \\
By giving advice & $275(78.6)$ \\
In keeping the children during the day & $39(11.1)$ \\
During a stay & $36(10.2)$ \\
Age of commencement of day-time toilet & \\
training (months) & \\
$\leq 12$ & $142(40.6)$ \\
$13-18$ & $80(22.9)$ \\
19 - 24 & $74(21.1)$ \\
25 - 30 & $31(9.0)$ \\
$\geq 31$ & $12(3.4)$ \\
Yet to start & 0 \\
Do not remember & $11(3.1)$ \\
Age of commencement of toilet training at & \\
night (months) & \\
$\leq 12$ & $124(35.4)$ \\
$13-18$ & $79(22.6)$ \\
19 - 24 & $86(24.6)$ \\
$25-30$ & $30(8.6)$ \\
$\geq 31$ & $21(6.0)$ \\
Do not remember & $7(2.0)$ \\
Yet to start & $3(0.9)$ \\
Dryness during afternoon nap & \\
Yes & $153(43.7)$ \\
No & $119(34.1)$ \\
Do not remember & $78(22.3)$ \\
Type of diaper used & \\
Cotton & $25(6.6)$ \\
Flannel & $3(0.9)$ \\
Disposable & $317(83.7)$ \\
Plastic pants & $4(1.1)$ \\
Method used & \\
Urinate at fixed time & $163(46.6)$ \\
Remove the diaper & $105(30.0)$ \\
On demand of the child & $47(13.4)$ \\
Reward & $8(2.2)$ \\
Punish & $8(2.3)$ \\
Imitation of parent or older sibling & $9(2.6)$ \\
Do not remember & $10(2.9)$ \\
&
\end{tabular}

participants $(67.7 \%, n=237)$ had children who were $\leq 5$ years old, $30.6 \%$ $(n=107)$ were between 5 and 10 years old, $19.1 \%(n=67)$ were $10-15$ years old, and $11.7 \%(n=41)$ were $>15$ years old.

\section{Method and age at commencement of toilet training}

A total of $309(88.3 \%)$ of the respondents participated in the toilet training of their own children. The remaining respondents left the toilet training to either a grandparent, caregiver or family relative (Fig. 1). A total of 275 (78.6\%) participated in toilet training by giving advice while the others participated in the toilet training of their grandchildren when the children were in their custody during the day or during a brief visit. Table 2 shows the method and age at commencement of toilet training of the children. The parents considered the age of the child as the most common reason for commencement of toilet training (Fig. 2).

Toilet training was commenced at $\leq 12$ months in the majority of the children during the day and night at $40.6 \%$ and $35.4 \%$, respectively. A total of $153(43.7 \%)$ of the respondents commenced toilet training 
Table 3. Age of attainment of continence, location and duration of training $(N=350)$

\begin{tabular}{ll}
\hline Variable & $\boldsymbol{n}(\%)$ \\
\hline Duration of toilet training for continence (months) & \\
$\leq 1$ & \\
$1-6$ & $55(15.7)$ \\
$7-12$ & $129(36.9)$ \\
$\geq 12$ & $84(24.0)$ \\
Still wet & $75(21.4)$ \\
& $7(2.0)$ \\
Where the training mainly took place & \\
At home & $310(88.6)$ \\
With grandparent & $8(2.3)$ \\
In reception class & $7(2.0)$ \\
In crèche & $25(7.1)$ \\
Age of attainment of night-time continence & \\
(months) & \\
$<12$ & $70(20.0)$ \\
$12-18$ & $104(29.7)$ \\
$19-30$ & $84(24.0)$ \\
$31-60$ & $46(13.1)$ \\
$>61$ & $16(4.6)$ \\
Still wet & $30(8.6)$ \\
Age of attainment of day-time continence (months) & \\
$<12$ & $117(33.4)$ \\
$12-18$ & $68(19.4)$ \\
$19-24$ & $104(29.7)$ \\
$25-30$ & $30(8.6)$ \\
$\geq 31$ & $21(6.0)$ \\
Do not remember & $7(2.0)$ \\
Yet to start & $3(0.9)$ \\
&
\end{tabular}

during an afternoon nap. Disposable diapers were the most commonly used diapers. The most common method of toilet training was allowing the child to urinate at fixed time intervals (46.6\%) and the least common method was by either reward or punishment.

\section{Attainment of continence}

The duration of toilet training was $1-6$ months for $36.9 \%(n=129)$ of the children; the shortest duration of training was $<1$ month. Training took place at home in $88.6 \%(n=310)$ of the children, with $7.1 \%(n=25)$ at the crèche. Continence was described for day- and night-time. The modal age at attainment of daytime continence in the wards of the participants was $<12$ months of age, closely followed by children age $19-24$ months (33.4 and 29.7\%, respectively). By 30 months of age $91.1 \%(n=319)$ of the children had attained daytime continence. Contrary to the daytime continence, 29.7\% ( $n=104)$ attained night-time continence between 12 and 18 months of age. Similar to the finding of the daytime continence, by 30 months of age the majority of the children, $86.9 \% \quad(n=304)$ had attained night-time continence. A total of $4.6 \%(n=16)$ achieved night time continence after 5 years of age while $30(8.6 \%)$ had not achieved continence at the time of this study. Among the 30 children who were still incontinent at night, the age at commencement of their toilet training was 18 - 24 months (13.3\%), >30 months $(13.3 \%),<1$ year $(16.7 \%)$, 12 - 18 months (23.3\%) and 24 - 30 months (33.3\%) Table 3.

\section{Comparison between private and public hospitals}

The age at attainment of night-time continence, place of training and who was in charge of the training were compared for private and public hospitals. There were no significant differences in results between private and public hospitals $(p>0.61)$. However, there was a significant difference in the age of attainment of night-time continence $(p<0.05)$ in both study centres. While most of the children from the public hospital
Table 4. Comparison between public and private hospitals in relation to toilet training

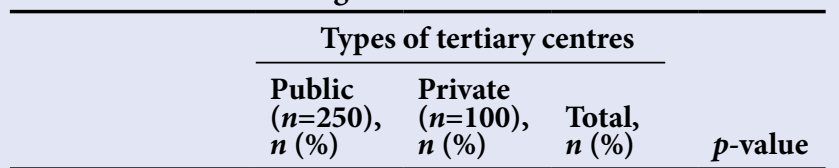

Who was in

charge of toilet

training?

$\begin{array}{lllll}\text { Parent } & 217(88.8) & 92(92.0) & 309(88.3) & 0.427 \\ \text { Grandparent } & 11(4.4) & 4(4.0) & 15(4.3) & \\ \text { Caregiver } & 15(6.0) & 2(2.0) & 17(4.9) & \\ \text { Relations } & 7(2.8) & 2(2.0) & 9(2.6) & \end{array}$

Age at attainment

of night-time

continence

(months)

$\begin{array}{lllll}\leq 12 & 57(22.8) & 13(13.0) & 70(20.0) & \\ 13-18 & 82(32.8) & 22(22.0) & 104(29.7) & 0.002^{*} \\ 19-24 & 47(18.8) & 37(37.0) & 84(24.0) & \\ 25-30 & 31(12.4) & 15(15.0) & 46(13.1) & \\ \geq 31 & 14(5.6) & 2(2.0) & 16(4.6) & \\ \text { Still wet } & 19(7.6) & 11(11.0) & 30(8.6) & \end{array}$

Place of toilet

training

$\begin{array}{lllll}\text { At home } & 219(87.6) & 91(91.0) & 310(88.6) & \\ \begin{array}{l}\text { With } \\ \text { grandparent }\end{array} & 7(2.8) & 1(1.0) & 8(2.7) & 0.613 \\ \begin{array}{l}\text { In reception } \\ \text { At crèche }\end{array} & 6(2.4) & 1(1.0) & 7(2.0) & \\ & 18(7.2) & 7(7.0) & 25(7.1) & \end{array}$

Age when toilet training commenced (months)

$\begin{array}{lllll}\leq 12 & 92(36.8) & 32(32.0) & 124(35.4) & \\ 13-18 & 59(23.6) & 20(20.0) & 79(22.6) & \\ 19-24 & 55(22.0) & 31(31.0) & 86(24.6) & 0.414 \\ 25-30 & 20(8.0) & 10(10.0) & 30(8.6) & \\ \geq 31 & 17(6.8) & 4(4.0) & 21(6.0) \\ \text { Still wet } & 4(1.6) & 3(3.0) & 7(2.0) \\ \begin{array}{l}\text { Do not } \\ \text { remember }\end{array} & 3(1.2) & 0 & 3(0.9) \\ \text { *Statistically significant. } & & & & \end{array}$

achieved continence between 12 and 18 months, most of the children at the private hospital attained continence at a more advanced age of 18 - 30 months. Also, the age at which toilet training was commenced in the public hospital was mainly $\leq 12$ months. The children from the private hospital commenced training at either $\leq 12$ months or 19 - 24 months (Table 4).

\section{Test of associations}

The test of association was computed for variables such as who was in charge of toilet training, age at which the child commenced training, method used and duration of toilet training for continence against age at 
Table 5. Test of association among different variables and age of attainment of day-time continence

\begin{tabular}{|c|c|c|c|c|c|c|c|c|}
\hline & \multicolumn{7}{|c|}{ Age of attainment of day time continence (months) } & \\
\hline & $<12$ & $12-18$ & $19-30$ & $31-60$ & $>61$ & Still wet & $\begin{array}{l}\text { Yet to } \\
\text { start }\end{array}$ & \\
\hline $\begin{array}{l}\text { Age of commencement of day-time } \\
\text { toilet training (months) }\end{array}$ & & & & & & & & \multirow{7}{*}{$\begin{array}{l}\chi^{2}=781.377 \\
p=0.000\end{array}$} \\
\hline$\leq 12$ & $114(97.4)$ & $26(38.2)$ & $1(1.0)$ & $1(3.3)$ & 0 & 0 & 0 & \\
\hline $13-18$ & 0 & $42(61.8)$ & $29(27.9)$ & $2(6.7)$ & 0 & $7(100)$ & 0 & \\
\hline $19-24$ & 0 & 0 & $66(63.5)$ & $3(10.0)$ & $5(23.8)$ & 0 & 0 & \\
\hline $25-30$ & 0 & 0 & $6(5.8)$ & $23(76.7)$ & $2(9.5)$ & 0 & 0 & \\
\hline$\geq 31$ & 0 & 0 & 0 & 0 & $9(42.9)$ & 0 & $3(100)$ & \\
\hline Do not remember & $3(2.6)$ & 0 & $2(1.9)$ & $1(3.3)$ & $5(23.8)$ & 0 & 0 & \\
\hline \multicolumn{9}{|l|}{$\begin{array}{l}\text { Duration of toilet training for } \\
\text { continence (months) }\end{array}$} \\
\hline$<1$ & $36(30.8)$ & $12(17.6)$ & $1(1.0)$ & 0 & $4(19.0)$ & 0 & $2(66.7)$ & \multirow{5}{*}{$\begin{array}{l}\chi^{2}=467.232 \\
p=0.000\end{array}$} \\
\hline $1-6$ & $81(69.2)$ & $34(50.0)$ & $2(1.9)$ & 0 & $7(33.3)$ & $4(57.1)$ & $1(33.3)$ & \\
\hline $7-12$ & 0 & $9(13.2)$ & $15(14.4)$ & $28(93.3)$ & $10(47.6)$ & 0 & 0 & \\
\hline$>12$ & 0 & $13(19.1)$ & $82(78.8)$ & $2(6.7)$ & 0 & 0 & 0 & \\
\hline Still wet & 0 & 0 & $4(3.8)$ & 0 & 0 & $3(42.9)$ & 0 & \\
\hline \multicolumn{9}{|l|}{ Who was in charge of training } \\
\hline Parents & $107(91.5)$ & $63(92.6)$ & $90(86.5)$ & $19(63.3)$ & $21(100)$ & $6(85.7)$ & $3(100)$ & \multirow{4}{*}{$\begin{array}{l}\chi^{2}=88.611 \\
p=0.000\end{array}$} \\
\hline Grandparents & $6(5.1)$ & $1(1.5)$ & $7(6.7)$ & 0 & 0 & $1(14.3)$ & 0 & \\
\hline Caregiver & $4(3.4)$ & $3(4.4)$ & $7(6.7)$ & $3(10.0)$ & 0 & 0 & 0 & \\
\hline Relatives & 0 & $1(1.5)$ & $0(0.0)$ & $8(26.7)$ & 0 & 0 & 0 & \\
\hline \multicolumn{9}{|l|}{ Method of toilet training } \\
\hline Urinate at fixed intervals & $75(64.1)$ & $21(30.9)$ & $54(51.9)$ & $2(6.7)$ & $8(38.1)$ & $2(28.6)$ & $1(33.3)$ & \multirow{7}{*}{$\begin{array}{l}\chi^{2}=248.912 \\
p=0.000\end{array}$} \\
\hline Remove diaper & $19(16.2)$ & $35(51.5)$ & $41(39.4)$ & $2(6.7)$ & $5(23.8)$ & $3(42.9)$ & 0 & \\
\hline On demand of the child & $23(19.7)$ & $4(5.9)$ & $2(1.9)$ & $8(26.7)$ & $8(38.1)$ & $2(28.6)$ & 0 & \\
\hline Reward & 0 & 0 & 0 & $7(23.3)$ & 0 & 0 & $1(33.3)$ & \\
\hline Punishment & 0 & $4(5.9)$ & $4(3.8)$ & 0 & 0 & 0 & 0 & \\
\hline Imitation of parent/older sibling & 0 & $4(5.9)$ & 0 & $5(16.7)$ & 0 & 0 & 0 & \\
\hline Do not remember & 0 & $0(0.0)$ & $3(2.9)$ & $6(20.0)$ & 0 & 0 & $1(33.3)$ & \\
\hline
\end{tabular}

attainment of both day- and night-time continence. It was observed that there was significant association among all those variables tested against age at attainment of day- and night-time continence $(p \leq 0.05)$. Mothers and grandparents were in charge of toilet training in the majority of children who were dry during the night before 12 months of age. Toilet training was commenced in children within 18 months of birth in the majority of children who were continent before 30 months. The most common method used in children who were continent before 18 months, was urinating at fixed time points. A toilet training period of $1-6$ months was noticed most among children who became continent at night before 18 months (Table 5).

\section{Discussion}

There are limited reports on toilet training in children in Africa. This study was conducted to describe the toilet training practices and factors, if any, which influenced the age of continence in Nigerian children.

In this study, toilet training was initiated at $\leq 12$ months in most of the subjects. The findings in this regard contradict reports from previous studies where toilet training started at a later age of $18-24$ months. ${ }^{[4,7]}$
The reason for this difference was not obvious. Possible explanations may be the difference in race, culture and beliefs among the subjects. This is because the present study included an African population group, while previous studies had been conducted in developed countries. It has been shown in a previous report that, among other factors, race affects the age at which toilet training is initiated. ${ }^{[2,32]}$ To our knowledge, there are no reports on the association, if any, between race and the age at initiation of toilet training. Different methods have been used to toilet train children. In the present study, children were asked to urinate at a fixed time. This involved removing the diapers and allowing for urination at fixed times. This bears semblance with the assisted infant toilet training method - a parent-oriented training method. ${ }^{[33]}$ This method existed centuries before the Western methods were described. It is popular among populations in China, India, South and Central America and less popular in North America and European countries. De Vries et al. ${ }^{[6]}$ studied this method among the Digo tribe in East Africa and noted that it was effective and resulted in early achievement of continence. The implication of this finding is that the advent of westernisation has not affected the age-old traditional method of toilet training in Nigeria. 
Table 5. (continued) Test of association among different variables and age of attainment of night-time continence

\begin{tabular}{|c|c|c|c|c|c|c|c|}
\hline & \multicolumn{6}{|c|}{ Age of attainment of night-time continence (months) } & \\
\hline & $<12$ & $12-18$ & $19-30$ & $31-60$ & $>61$ & Still wet & \\
\hline \multicolumn{8}{|l|}{$\begin{array}{l}\text { Age of commencement of toilet training } \\
\text { at night (months) }\end{array}$} \\
\hline$\leq 12$ & $64(91.4)$ & $58(55.8)$ & $1(1.2)$ & $1(2.2)$ & 0 & 0 & \multirow{7}{*}{$\begin{array}{l}\chi^{2}=533.445 \\
p=0.000\end{array}$} \\
\hline $13-18$ & 0 & $46(44.2)$ & $19(22.6)$ & $7(15.2)$ & 0 & $7(23.3)$ & \\
\hline $19-24$ & 0 & 0 & $63(75.0)$ & $11(23.9)$ & $10(62.5)$ & $2(6.7)$ & \\
\hline $25-30$ & 0 & 0 & 0 & $16(34.8)$ & $6(37.5)$ & $8(26.7)$ & \\
\hline$\geq 31$ & 0 & 0 & 0 & $11(23.9)$ & 0 & $10(33.3)$ & \\
\hline Do not remember & $6(8.6)$ & 0 & $1(1.2)$ & 0 & 0 & 0 & \\
\hline Yet to start & 0 & 0 & 0 & 0 & 0 & $3(10.3)$ & \\
\hline \multicolumn{8}{|l|}{ Duration of toilet training for continence } \\
\hline$<1$ month & $24(34.3)$ & $23(22.1)$ & $1(1.2)$ & $2(4.3)$ & $5(31.2)$ & 0 & \multirow{5}{*}{$\begin{array}{l}\chi^{2}=273.882 \\
p=0.000\end{array}$} \\
\hline $1-6$ months & $46(65.7)$ & $33(31.7)$ & $29(34.5)$ & 0 & $7(43.8)$ & $14(46.7)$ & \\
\hline 7 - 12 months & 0 & $48(46.2)$ & $22(26.2)$ & $4(8.7)$ & $4(25.0)$ & $6(20.0)$ & \\
\hline$>12$ months & 0 & 0 & $28(33.3)$ & $40(87.0)$ & 0 & $7(23.3)$ & \\
\hline Still wet & 0 & 0 & $4(4.8)$ & 0 & 0 & $3(10.0)$ & \\
\hline \multicolumn{8}{|l|}{ Who was in charge of training? } \\
\hline Parents & $58(82.9)$ & $93(89.4)$ & $77(91.7)$ & $35(76.1)$ & $16(100)$ & $30(100)$ & \multirow{4}{*}{$\begin{array}{l}\chi^{2}=70.181 \\
p=0.000\end{array}$} \\
\hline Grandparents & $8(11.4)$ & $7(6.7)$ & 0 & 0 & 0 & 0 & \\
\hline Caregiver & $4(5.7)$ & $3(2.9)$ & $7(8.3)$ & $3(6.5)$ & 0 & 0 & \\
\hline Relatives & 0 & $1(1.0)$ & 0 & $8(17.4)$ & 0 & 0 & \\
\hline \multicolumn{8}{|l|}{ Method of toilet training } \\
\hline Urinate at fixed intervals & $28(40.0)$ & $51(49.0)$ & $53(63.1)$ & $9(19.6)$ & $8(50.0)$ & $14(46.7)$ & \multirow{7}{*}{$\begin{array}{l}\chi^{2}=185.931 ; \\
p=0.000\end{array}$} \\
\hline Remove diaper & $19(27.1)$ & $41(39.4)$ & $23(27.4)$ & $8(17.4)$ & $0(0.0)$ & $14(46.7)$ & \\
\hline On demand of the child & $23(32.9)$ & $4(3.8)$ & $0(0.0)$ & $10(21.7)$ & 850.(0) & $2(6.7)$ & \\
\hline Reward & 0 & 0 & 0 & $8(17.4)$ & 0 & 0 & \\
\hline Punishment & 0 & $4(3.8)$ & $4(4.8)$ & 0 & 0 & 0 & \\
\hline Imitation of parent or older sibling & 0 & $4(3.8)$ & 0 & $5(10.99)$ & 0 & 0 & \\
\hline Do not remember & 0 & 0 & $4(4.8)$ & $6(13.0)$ & 0 & 0 & \\
\hline
\end{tabular}

The duration of toilet training in most of the respondents in the present study was 1 - 6 months. The finding in this regard is incongruent with report from previous studies. ${ }^{[2,4,34]}$ The general trend noted from previous reports was that training is completed within 1 year of commencement. It was therefore not surprising that $70 \%$ of the children were continent within 1 year of commencement of training in the present study.

In the present study, the age at attainment of day- and night-time continence was $<12$ and $12-18$ months, respectively. This finding was contrary to reports from previous studies. Daytime continence was achieved at 32.5 and 35 months in boys and girls, respectively, in the report by Schum et al. ${ }^{[35]}$ Also, a recent report has shown that only $40-60 \%$ of children completed training by 36 months. The general trend noted from previous reports was that complete continence was attained at 30 - 40 months - much later than the age reported in the present study. A possible reason may be because of the earlier timing of initiation of toilet training and the method used, as noted earlier. It has been observed that age at attainment of day- or night-time continence is dependent on factors such as timing of initiation and method used. Even if the age at attainment of continence in the present study is earlier than in previous reports, the finding in this regard is not far-fetched. This is because bladder development and maturation occur at about 18 months of age, which was the time reported by the majority of the respondents in the present study.

Attempts have been made to document factors which affect toilet training from previous studies. In the current study, factors which affected the time of attainment of continence were the individuals responsible for toilet training, time of initiation of toilet training and the method of toilet training. Most of the children who achieved continence within 1 year of commencement were trained by their mothers. This is not surprising because the mothers are more patient or tolerant compared with the fathers or any other relatives/persons. Children who commenced toilet training within 1 year of life also achieved continence earlier. It has been shown that the duration of toilet training is related to the age at initiation of training. ${ }^{[36]}$ Children who commenced training earlier achieved continence earlier. ${ }^{[4,36]}$ But this is not always the case, because some children may develop problems along the line of training and if this not handled properly by 
the guardian/parent, it may hamper training and prolong the duration of training and time to achieve continence. Children who were trained by urinating at fixed intervals achieved continence earlier. There are no randomised studies on the assisted infant training method, but studies that have been done with the other training methods have shown that those methods affected the time of continence. ${ }^{[33]}$ There are, however, conflicting reports in this regard.

The present study compared findings from caregivers who attended private and public tertiary hospitals. The sociodemographic characteristics were similar between the respondents of both hospitals. It was therefore not surprising that there were similar findings in both children.

\section{Conclusion}

Nigerian children are being toilet trained at an earlier age compared with children in developed countries. Also, the age-old traditional method of toilet training is still practised in Nigeria despite the influence of the Western world on our way of life. The age of attaining continence is also lower than for developed countries.

Acknowledgements. Sincere appreciation to the parents of the children. Author contributions. AUS developed the concept, literature review, data collection and analysis and discussion. OAO did data collection and analysis. ADM helped with the literature review, analysis and discussion. IS contributed to the concept and review of manuscript.

Funding. None.

Conflicts of interest. None.

1. Brazelton TB, Christopher E, Frauman A, et al. Instruction, timeliness and medical influences affecting toilet training. Pediatrics 1999;103(6):1353-1358.

2. Yang SS-D, Zhao L-L, Chang S-J. Early initiation of toilet training for urine was associated with early urinary continence and does not appear to be associated with bladder dysfunction. Neurourol Urodyn 2011;30(7):1253-1257. https://doi. org/10.1002/nau.20982

3. Hinde M, Hjertonsson M, Broberg A. [Low self-esteem of children with enuresis. Mental and social health compared in different groups]. Lakartidningen 1995;92(36):3225-3229.

4. Bakker E, Wyndaele J. Changes in the toilet training of children during the last 60 years : The cause of an increase in lower urinary tract dysfunction ? BJU Int 2000;86(3):248-252. https://doi.org/10.1046/j.1464-410x.2000.00737.x

5. Kinservik M, Friedhoff M. Control issues in toilet training. Pediatr Nurs 2000;26(3):267-272.

6. De Vries M, De Vries M. Cultural relativity of toilet training readiness: A perspective from East Africa. Pediatrics 1977;60(2):170-177.

7. Blum NJ, Taubman B, Nemeth N. Why is toilet training occurring at older ages? A study of factors associated with later training. J Pediatr 2004;145(1):107-111. https://doi.org/10.1016/j.jpeds.2004.02.022

8. Toilet Training Guidelines: Parents - The Role of the Parents in Toilet Training. Pediatrics 1999;103(6 Pt 2):1362-1363.

9. Vermandel A, Van Kampen M, Van Gorp C, Wyndaele J-J. How to toilet train healthy children? A review of the literature. Neurol Urodyn 2008;27(3):162-166. https://doi.org/10.1002/nau.20490

10. Hellström A. Influence of potty training habits on dysfunctional bladder in children. Lancet 2000;356(9244):1787. https://doi.org/10.1016/s01406736(00)03228-1

11. Joinson C, Heron J, von Gontard A, Butler U, Emond A, Golding J. A prospective study of age at initaition of toilet training and subsequent day time bladder control in school-aged children. J Dev Behav Pediatr 2009;30(5):385-393. https:// doi.org/10.1097/dbp.0b013e3181ba0e77

12. Mota DM, Barros AJ. Toilet training: situation at 2 years of age in a birth cohort. J Pediatr (Rio J) 2008;84(5):455-462. https://doi.org/10.2223/jped.1832
13. Duong T, Jansson U, Holmdahl G, Sillen U, Hellstrom A. Development of bladder control in the first year of life in children who are potty trained early. J Pediatr Urol 2010;6(5):501-505. https://doi.org/10.1016/j.jpurol.2009.11.002

14. Brazelton TB. A child-oriented approach to toilet training. Pediatrics 1962;29(1):121-128.

15. Foxx RM, Azrin NH. Dry pants: A rapid method of toilet training children. Behav Res Ther 1973;11(4):435-442. https://doi.org/10.1016/0005-7967(73)90102-2

16. Stadtler AC, Gorski PA, Brazelton TB. Toilet training methods, clinical interventions and recommendations. Pediatrics 1999;103(supp 3):1359-1368.

17. American Academy of Pediatrics. Toilet Training. Guidelines for Parents. Illinois: AAP, 1998.

18. Community Paediatrics Committe C. Toilet learning: Anticipatory guidance with a child-oriented approach. J Paediatr Child Health 2000;5(6):333-335. https://doi.org/10.1093/pch/5.6.333

19. De Paepe H, Hoebeke P, Renson C, Van Laecke C, Raes A, Van Hoecke E. Pelvic-floor therapy in girls with recurrent urinary tract infections and dysfunctional voiding. Br J Urol 1998;81(S3):109-113. https://doi.org/10.1046/ j.1464-410x.1998.00021.x

20. Polaha J, Warzak W, Dittmer-Mcmahon K. Toilet training in primary care: current practice and recommendations from behavioural pediatrics. J Dev Behav Pediatr 2002;23(6):424-429. https://doi.org/10.1097/00004703-200212000-00005

21. Schmitt B. Toilet training: Getting it right the first time. Contemp Pediatr 2004;21:105-122.

22. Mota DM, Barros AJD. Toilet training: Methods, parental expectations and associated dysfunctions. Jornal de Pediatria 2008;84(1):9-17. https://doi. org/10.2223/jped.1752

23. Caldwell P, Edgar D, Hodson E, Craig J. Bedwetting and toileting problems in children. Med J Aust 2005;182:190-195.

24. Hjalmas K. Still much ignorance about the fact that children with enuresis need treatment. Lakartidningen 2004;101:276-280.

25. Yeung C. Nocturnal enuresis (bedwetting). Curr Opin Urol 2003;13(4):337-343. https://doi.org/10.1097/00042307-200307000-00011

26. Abramovitch IB, Abramovitch $\mathrm{HH}$. Enuresis in cross-cultural perspective: a comparison of training for elimination control in three Isreali ethnic groups. J Soc Psychol 1989;129(1):47-56. https://doi.org/10.1080/00224545.1989.9711698

27. Fishman L, Rappaport L, Cousineau D, Nurko S. Early constipation and toilet training in children with encopresis. J Pediatr Gastroenterol Nutr 2002;34(4):385388. https://doi.org/10.1097/00005176-200204000-00013

28. Chiozza ML, Bernardinelli L, Caione $\mathrm{P}$, et al. An Italian epidemiological multicentre study of nocturnal enuresis. Br J Urol 1998;81(s3):86-89. https://doi. org/10.1046/j.1464-410x.1998.00015.x

29. De Paepe H, Renson C, Van Laecke E, Raes A, Vande Walle J, Hoebeke P. Pelvicfloor therapy and toilet training in young children with dysfunctional voiding and obstipation. Br J Urol 2000;85(7):889-893. https://doi.org/10.1046/j.1464410x.2000.00664.x

30. Hellstrom A, Hjalmas K, Jodal U. Rehabilitation of the dysfunctional bladder in children: Method and 3-year follow up. J Urol 1987;138(4):847-849. https://doi. org/10.1016/s0022-5347(17)43395-7

31. Oyedeji GA. Socio economic and cultural background of hospitalised children in Ilesha. Niger J Paediatr 1985;12(4):111-117.

32. Horn I, Brenner R, Rao M, Cheng T. Beliefs about the appropriate age for initiating toilet training: are there racial and socioeconomic diffrences? J Pediatr 2006;149(2):165-168. https://doi.org/10.1016/j.jpeds.2006.03.004

33. Choby BA, George S. Toilet training. Am Fam Physician 2008;78(9):1059-1064.

34. Bloom DA, Seely WW, Ritchey ML, McGuire EJ. Toilet habits and continence in children: An opportunity in search of normal parameters. JUrol 1993;149(5):10871090. https://doi.org/10.1016/s0022-5347(17)36304-8

35. Schum TR, Kolb TM, McAuliffe TL, Simms MD, Underhill RL, Lewis M. Sequential acquisition of toilet-training skills: a descriptive study of gender and age differences in normal children. Pediatrics 2002;109(3):e48-49. https://doi. org/10.1542/peds.109.3.e48

36. Blum NJ, Taubman B, Nemeth N. Relationship between age at initiation of toilet training and duration of training: A prospective study. Pediatrics 2003;111(4):810-814. https://doi.org/10.1542/peds.111.4.810 